\title{
El comercio gaditano con el Perú entre 1814 y 1826, ¿desaparición o adaptación?/
}

\author{
The Trade from Cadiz to Peru, 1814-1824, \\ Disappearance or Adaptation?
}

\author{
Jesús Ruiz de Gordejuela Urquijo \\ orcid.org/0000-0002-7016-6837 \\ Universidad Rey Juan Carlos
}

\begin{abstract}
El artículo se propone analizar y aportar nuevas conclusiones sobre el comercio gaditano con el Perú entre los años 1814 y 1826. Para ello nos hemos servido de la correspondencia inédita del comerciante Francisco de Carranza, testigo directo de los acontecimientos, con los más importantes comerciantes limeños. Conoceremos las enormes dificultades que padecieron estos hombres de negocios en tiempos de tribulación y las estrategias utilizadas para sobrevivir en un comercio que parecía abocado a su fin. Asimismo podremos saber si desapareció o se adaptó el comercio entre ambos territorios.
\end{abstract}

Palabras Clave: Cádiz; Perú; Crisis del comercio; Siglo XIX; Francisco de Carranza; Francisco Xavier de Izcue; Independencia del Perú; Inglaterra.

This research article puts forward to analize and contribute new conclusions about the trade from Peru between 1814 y 1826. For this purpose, we made use of unpublished correspondence of the "peruano» called Francisco de Carranza, a direct witness of those events, with the most important businessmen from Peru. We could know the huge difficulties that had suffered those businessmen in times of tribulation and the strategies used in order to survive in a trade bound to fail. Furthermore, we will be able to get to know if it disappeared or adapted itself between both territories.

Keywords: Cadiz; Peru; Crisis of trade; 19th Century; Francisco de Carranza; Francisco Xavier de Izcue; Independence of Peru; England.

Copyright: @ 2016 CSIC. Este es un artículo de acceso abierto distribuido bajo los términos de una licencia de uso y distribución Creative Commons Attribution (CC-by) España 3.0. 
El buen oficio ejercido por historiadores como Ramiro Flores Guzmán, Paúl Rizo-Patrón Boylan, Deolinda Villa, Carmen Parrón, Scarlett O'Phelan, Brian Hamnett, Antonio García-Baquero, Jesús Turiso, Manuel Bustos Rodríguez y Alberto Flores Galindo nos ha ayudado a conocer mejor este episodio tan destacado en la historia del Perú y España. Pero entre todos emergen dos figuras que han desentrañado con sus investigaciones el comercio limeño del primer cuarto de siglo XIX: Carlos Malamud, maestro para muchos de los historiadores que nos hemos acercado a esta temática, y Cristina Ana Mazzeo de Vivó. A modo de síntesis podemos decir que Malamud en fechas tan tempranas como 1978 nos abría el camino de la investigación del comercio gaditano con el Perú con su trabajo «El fin del comercio colonial: una compañía comercial gaditana del siglo XIX», y que años después Mazzeo ha continuado en su Perú adoptivo con una rica producción bibliográfica. Esta autora ya nos advertía de que la limitación de fuentes originales impedía presentar un estudio completo de las relaciones mercantiles entre estos dos importantes puertos de Cádiz y El Callao. La suerte nos ha permitido acceder a un archivo inédito de más de 10.000 documentos perteneciente al comerciante vizcaíno Francisco de Carranza y Ortiz, quien ejerció el comercio en Cádiz entre los años 1794 y 1846, fecha esta última de su fallecimiento, es decir medio siglo de historia de las relaciones mercantiles con el Perú y la Nueva España. ${ }^{1}$ Con este rico legado pretendemos completar, en la medida de lo posible este vacío documental y mostrar asimismo episodios de la vida cotidiana de estos comerciantes ultramarinos.

Durante los primeros años del siglo XIX, El Callao ocupó el segundo lugar en importancia en el contexto global del comercio con España a través de Cádiz. Nueva España absorbía la mitad de las exportaciones de Cádiz, con un 55,2 \%, siguiendo en importancia El Callao con un 17,2 \% y en tercer lugar se encontraba el Río de la Plata con el 11,5\% de las exportaciones de Cádiz. El resto se distribuía entre Cuba y Puerto Rico (6,5\%), Venezuela $(6,1 \%)$ y Nueva Granada $(2,7 \%){ }^{2}$

Respecto al origen geográfico de los comerciantes españoles en el Perú destaca de manera clara la presencia vasconavarra; de hecho, entre 1787 y 1810 el $70 \%$ de los pasajeros que pasaron al Perú procedían de

1 Este archivo particular sito en la villa de Lanestosa (Bizkaia) y compuesto fundamentalmente por una importante colección epistolar, nos ha sido facilitado gracias a la generosidad del investigador Manuel de la Cruz, director de la página web Historias de Lanestosa.

2 Mazzeo, 2010, 267. 
las provincias cantábricas y de estos el $46 \%$ del País Vasco y Navarra. ${ }^{3}$ Desde que en 1810 se levantaran los primeros movimientos independentistas en el continente americano los comerciantes peruanos y en especial los limeños, representados por su consulado, cerraron filas y a través de numerosos e importantes donativos y préstamos permitieron a lo largo de casi 15 años mantener la esperanza de continuar bajo el amparo del rey de España. El control del comercio americano estuvo en manos de los principales exportadores gaditanos al Perú y en sus colegas peruanos que gozaban de un alto grado de confianza, ya sea por vínculos familiares o de paisanaje.

Los ricos miembros del consulado de Lima ejercieron su hegemonía en el comercio oceánico desde el sur chileno hasta incluso los lejanos puertos novohispanos de San Blas o Mazatlán. De la importancia del Tribunal del Consulado de Lima, cuya Junta General estaba integrada por 200 personas en 1815, podemos decir que en sus arcas guardaba cerca de 5 millones de $\operatorname{pesos}^{4}$ y durante sus últimos años de existencia estuvieron a la cabeza de esta institución, entre otros, los hermanos Antonio y Matías de Elizalde, quienes habían relevado a Javier María de Aguirre, y finalmente su paisano Francisco Xavier de Izcue.

En este comercio entre Cádiz y El Callao podemos distinguir básicamente dos etapas determinadas por los conflictos bélicos en los que España estuvo involucrada: La primera entre los años 1814 y 1820, es decir desde el final de la guerra de independencia en la península hasta los momentos previos a la independencia del Perú, en donde se manifestó un claro aumento del tráfico marítimo en el que España pretendía ocupar de nuevo un espacio en donde cada vez era menos protagonista y en un mar cada vez está más controlado por las naciones independientes; y la segunda, desde la citada proclamación de la independencia del Perú en 1821 hasta la derrota final de las tropas realistas en el continente americano en la batalla de Ayacucho el 5 de diciembre de 1824 y el inicio de los primeros gobiernos patrios. ${ }^{5}$

3 Flores Galindo, 1984, 55. Malamud, 1978, 290.

4 Flores Galindo, 1984, 59.

5 Mazzeo, 1999, 1-15. En este trabajo la autora consulta los libros de Aduana del Callao para estudiar la salida de embarcaciones de este puerto entre los años 1783 y 1825 , aunque ya advierte que el año 1817 según estas fuentes marcó la desaparición total de llegada de barcos procedentes de Cádiz con la salida de 12 embarcaciones y a su vez nos indica que tampoco esta fuente resulta completa ya que no hay registro de salida de embarcaciones entre 1811-1813 y 1815-1816. 


\section{Primer periodo: 1814-1820}

En fechas previas a esta primera fase, la negociación con barcos neutrales benefició a los puertos distantes de los principales centros mercantiles, como el de Buenos Aires, Veracruz y el Caribe. Por tal razón, cuando en 1799 se quiso derogar la real orden y volver a los navíos de registro, no se logró ya que esta política beneficiaba a los comerciantes al contar con un flete más barato y, a su vez, la corona recibía ingresos fiscales por los derechos que debían pagar los consignatarios extranjeros al retirar del país mercancías, oro y plata. Por lo tanto, la corona siguió entregando licencias comerciales especiales con la única condición de transportar mercadería legal con tal de que no perjudicase a la industria del país, tales como ropa hecha, cueros curtidos, suelas, botas, zapatos, sillas, mesas, cómodas, coches, calesas, sillas de montar y demás manufacturas de talabartería, velas de cera, esperma y sebo.

A pesar de que entre 1802 y 1804, el tráfico comercial entre Cádiz y América notó un aumento al coincidir con un breve período de paz con Inglaterra, lo cierto es que tras la alianza con Francia se produjo la mayor contracción del comercio ultramarino. Tan solo los buques ingleses que llegaban al puerto gaditano fueron los encargados de mantener viva la red comercial con las colonias americanas hasta 1814 cuando España, victoriosa de la guerra de independencia, reabrió muy lentamente su tradicional comercio con el Perú. El incremento del contrabando en América y los estragos del corso fueron determinantes y prácticamente ya irresolubles para los intereses españoles en el continente americano.

La importación fluctuó entre uno y dos millones de pesos mientras que la exportación de caudales alcanzó un promedio de 3,5 millones de pesos con un máximo de 6.115.771 pesos en 1815 aunque según pasaron los años fue descendiendo hasta el mínimo en 1817 con la cifra de 1.782 .927 pesos.

Una de las primeras embarcaciones que llegaron a Cádiz tras la expulsión de las tropas napoleónicas fue la fragata Nuestra Señora del Carmen alias la Resolución que tras anclar en el puerto del Callao en agosto de 1814, zarpaba para finales de ese año rumbo a Cádiz «con registro de oro, plata y frutos» tras pagar por razón de flete $2,5 \%$. Entre los propietarios que embarcaron su plata destacaron ricos e importantes comerciantes limeños que aprovecharon estas primeras oportunidades de enviar dinero a sus consignatarios en Cádiz; podemos señalar a fray Rafael Castro (Colegio de 
Moquegua) (600 pesos en plata doble), Francisco Xavier de Izcue (8.136), Francisco Carranza (1.575), Francisco Ignacio de Alvizu (1.125), Juan Bautista de Gárate (2.000), Bartolomé de Lopetedi (5.000), Manuel de Acasuso (4.190), Sres. Paúl Larrieta y Cía. (10.000), José Celaya y Reguera (225), Juan Rangen Criado (3.000) y Diego de Aliaga (5.000), sumando la cifra total de 40.881 pesos de plata doble. ${ }^{6}$

Pronto apareció el corso frente a las costas del Perú y con ellos el miedo a ser capturados los barcos mercantes que hacían la ruta transoceánica. Francisco Xavier de Izcue escribió a su paisano Juan de Abajas Carranza de cómo no había llegado ningún barco al Callao procedente de Valparaíso tras haberse divisado cuatro embarcaciones sospechosas de ser «piratas del Río de la Plata que ha quedado desvanecido al comprobar que son balleneros con rasgos de contrabandistas». Asimismo Izcue era optimista respecto al comercio entre la metrópoli y el virreinato del Perú al conocer de los recientes éxitos del ejército realista en el Bajo Perú y «con este motivo empieza a ponerse en movimiento el comercio; la confianza va recuperándose y los efectos aunque no tomen mucho valor, a lo menos se costearán».

El temor a que los frutos del comercio fueran apresados por los corsarios obligaba a que se tomaran todas las precauciones posibles. Francisco de Carranza en 1816 escribía a su paisano Francisco María de Zuloaga indicándole claramente el modo de actuar con su plata. Un ejemplo de las medidas que debían tomar los depositarios lo tenemos en una carta que el citado Francisco de Carranza escribió poco tiempo después de su regreso a Cádiz en 1817 al comerciante limeño Saturnino de Barinaga, responsable de que su mercancía fuera bien vendida en tierras peruanas, en donde le insistía en que sus beneficios fueran embarcados rumbo a España en primer lugar en un buque de guerra tanto de bandera nacional como de neutrales y en su defecto en dos buques mercantes armados para que de este modo se redujera el riesgo de ser capturado por los muchísimos corsarios que infestaban tanto el Pacífico Sur como el Atlántico. En caso de no cumplir estos requisitos le instaba a que el capital obtenido lo depositara en manos de sus personas de confianza en Lima, Francisco Xavier Izcue y Juan de Abajas quienes se encargarían de enviarlo en el momento más conveniente. ${ }^{8}$

\footnotetext{
6 Registro de partidas de la fragata mercante Resolución, Cádiz, 13 de marzo de 1815, Archivo particular del comerciante Francisco de Carranza, Lanestosa, Bizkaia (en adelante AFC).

7 Carta de Francisco Xavier de Izcue a Juan de Abajas, Lima, 18 de abril de 1815, AFC.

8 Carta de Francisco de Carranza a Saturnino de Barinaga, Cádiz, 21 de abril de 1817, AFC.
} 
Para mostrar la tipología de mercancías que eran demandadas por los comerciantes limeños en estos primeros momentos del restablecido comercio interoceánico nos pueden servir de ejemplo los productos embarcados en las fragatas Cinco Hermanos y en el Alcides. En la primera de estas, el comerciante Miguel del Camino envió por su propia cuenta y riesgo a Francisco Xavier de Izcue cuatro cajones con listonería, seda joyante de Murcia, tafetanes, pañuelos de seda y todo por un valor de 25.146 reales con un gasto de 2.264 (entre los que destacan el $3 \%$ de comisión de compra, corretaje y remesa $)^{9}$, mientras que el segundo buque que había partido del puerto de Cádiz el 25 de noviembre de 1814 llegó al puerto del Callao el 1 de abril de 1815, transportó 648 cabos de bayeta de pellón superfina a 87 pesos/cabo y 76 cajas toscas que contenían 1.540 piezas de panas, lo que ascendió a 962.935 reales de plata de los que José Xavier de Zuloaga poseía las dos terceras y el otro tercio (320.978 reales) pertenecía a la compañía comercial gaditana Viuda de Ruiz e hijo Terry.

Los tiempos de paz había que aprovecharlos y por ello era necesario cargar lo más rápidamente posible el barco para hacer el retorno sin demora. De este modo se lo manifestaba el armador de este barco al maestre Francisco de Carranza: «[...] lo conveniente de no perder momento en la descarga del buque a fin de que con la mayor actividad se disponga también lo necesario para la compra de frutos por nuestra cuenta y habilitación de retorno de la referida fragata, teniendo presente que nada será de más provecho para la expedición que un buen registro de plata». Ponía énfasis en que «para su regreso se aproveche bien el buque, pues lo pequeño de este obliga a que nada se desperdicie aunque vengan con alguna estrechez. Asimismo, procurará Vuestra Merced que en la cámara se coloquen los más pasajeros que puedan venir y que los pasajes sean proporcionados al mérito del buque». Las instrucciones de navegación no dejan de lado asuntos tan concretos como la necesidad de crear en el barco un espacio en donde se «lleven bien la oficialidad y pasajeros para evitarnos el disgusto que tendríamos si lo hubiese entre ellos con el mejor modo posible» así como instrucciones dirigidas a su capitán, Martín Revilla, para que cuando se acercase a la altura del Río de la Plata se alejase todo lo posible para eludir a los numerosos corsarios, para lo que le aconsejaba que siempre «hubiera hombres de descubierta en las crucetas para huir con tiempo de todo barco que divisen, aunque su apariencia no sea sospechosa y lo mismo al

9 Carta de Miguel del Camino a Francisco de Carranza, Cádiz, 7 de octubre de 1815, AFC. 
acercarse al Callao, donde no deben fondear hasta que mandando el bote a tierra y volviendo con las reseñas oportunas de inteligencia se asegurasen que no hay en tierra ninguna novedad funesta». ${ }^{10}$

\section{Estudio de caso: El Alcides}

La suerte de que el archivo particular de Francisco de Carranza tuviera entre sus fondos el sobordo del Alcides en su viaje de regreso a Cádiz desde El Callao en fechas tan tardías, nos permite ofrecer información novedosa en la que se muestran los principales actores del comercio tardocolonial hispanoperuano.

Nuestra Señora del Rosario, o más conocida por El Alcides, fue una fragata mercante forrada en cobre y armada de 10 cañones propiedad de la compañía gaditana Viuda de Ruiz e Hijo Terry. Como hemos podido leer en líneas anteriores, este buque fondeó en el puerto del Callao procedente de Cádiz el primero de abril de 1815, permaneciendo en esta bahía hasta el 25 de octubre de ese mismo año en que tomó vela de vuelta a España, fondeando en Cádiz el 29 de febrero de 1816, tras 127 días de navegación. El flete consistió en 671.000 pesos en plata (impuestos del $2 \%, 134.400$ reales de plata), 46.032 pesos en oro $(0,75 \%, 3.452,0,5$ reales de plata), 680 castellanos de oro $(0,75 \%), 16$ marcos de plata ( $2 \%$ de impuestos) y 707 quintales de cobre a 24 reales/q. (1.698 pesos). Asimismo transporta 6 barriles de vino moscatel a 80 reales de plata (48 pesos) embarcados por Francisco Xavier de Izcue de cuenta y riesgo y consignación en Cádiz de Juan Manuel de la Cruz, conde de Maule, un cajón de loza de Bucaro embarcado por Buenaventura Llavería de cuenta y riesgo de José Santiago Solo de Zaldívar y a consignación de Dionisio Prendergat y un cajón con alhajas y loza de Chile. ${ }^{11}$

Como hemos señalado anteriormente también estos barcos mercantes transportaban un grupo limitado de personas. En este caso el costo del pasaje ascendió a 600 pesos (6.000 reales de plata), cantidad nada despreciable si tenemos en cuenta que el sueldo de un empleado de almacén en aquellos días en Lima no superaba los 5 pesos al mes. En esta ocasión el

10 Factura de Viuda de Ruiz e Hijo Terry a Francisco de Carranza, Cádiz, 25 de noviembre de 1814, AFC.

11 Idem. 
pasaje estuvo compuesto por fray Juan de Dios Cabezudo con un criado negro, Francisco de Ortega Ramos y su hijo Isidoro, Bernabé Fernández, Luciano Murrieta y José Joaquín de Aramburu, quien falleció durante la travesía por lo que tan solo se le cobraron 300 pesos de la mitad del pasaje. Además de estos pasajeros viajaban los reos de estado Francisco Carrascón (de Cuzco) y José Mestra (de Lima).

El estudio del sobordo del Alcides nos permite conocer a los tres principales actores de este registro: los depositarios, los propietarios de los caudales y los consignatarios en el puerto de Cádiz. En esta rica e inédita documentación el maestre Francisco de Carranza registró toda la carga, incluidas las entradas de plata y oro que los depositarios le entregaban, en su mayor parte pertenecientes a ricos personajes de la sociedad virreinal, para que fuera trasladada a España con la mayor garantía de seguridad. Estos depositarios eran comerciantes limeños con importantes contactos en distintas plazas americanas y europeas que registraban tanto mercancías como plata y oro en el puerto del Callao en el barco que menos costes y más seguridad ofrecieran los maestres de las distintas naves que pretendían navegar al destino.

De los 321 registros de que consta este sobordo, 10 corresponden a cálices de oro y plata, joyas y perlas, mientras que casi la mitad del resto, 147, están compuestos de cantidades inferiores a los 1.000 pesos. La siguiente franja de valores lo conforman los depósitos de cantidades comprendidas entre los 1.000 y 2.000 con 59 registros, reduciéndose estos según ascienden las cantidades de plata enviada. En el Alcides se recibieron cinco partidas de entre 10.000 y 20.000 pesos, cuatro superiores a los 20.000 pesos y tan solo una partida que superó los 40.000 pesos.

Además de los comerciantes citados en el anexo n. ${ }^{\circ} 1$, otros muchos tan solo realizaron un único depósito en el buque Alcides. Entre estos últimos encontramos a personajes importantes del mundo mercantil peruano, tales como José Arizmendi (4.000 pesos), José Ignacio Palacios (5.000), José Sánchez Resa (7.500), Manuel Sobrado (10.000), Miguel Blanco (9.000), Miguel Jáuregui (10.000), Joaquín María Ferrer (4.000) y José Aguirre-Solarte (10.000).

Respecto al origen de los bienes depositados, estos procedían principalmente de la venta de los productos comprados en España por sus consignatarios y vendidos en el virreinato del Perú, y de la plata y oro fruto de años de capitalización. En cuanto a la proporción de uno u otro no estamos en condiciones de determinar su cuantía, aunque sí podemos asegurar que 
mientras se mantuvo el comercio entre España y el Perú, gran parte de las remesas enviadas a Cádiz y a otras plazas europeas fueron los beneficios obtenidos en las transacciones comerciales y destinadas a alimentar el flujo mercantil; ya con la independencia del virreinato se produjo la salida apresurada de la plata y oro de los españoles que abandonaron precipitadamente la nueva república.

\section{Tipología de las mercancías peruanas transportadas a Cádiz}

Además de plata y oro, El Alcides transportaba la no despreciable cantidad de 5.514 cargas de cacao de Guayaquil (48 reales carga) por valor de 26.468 pesos. Este solicitado producto representaba el $68 \%$ del total de las exportaciones a Cádiz y era controlado por los ricos comerciantes de los consulados de Lima y Cádiz. A partir de 1793 las exportaciones se mantuvieron en torno a las 20.000 cargas/año cifra que en el beneficioso año de 1817 ascendió a las 35.620 al precio de 81 libras carga. La apertura al comercio del cacao en 1796 del puerto novohispano de San Blas, y posteriormente de los puertos de Panamá, Sonsonate y Realejo, llegarán a absorber hasta el $27 \%$ de la producción total del cacao guayaquileño. ${ }^{12}$

RELACIÓN DE LAS CARGAS DE CACAO COMPRADAS EN GUAYAQUIL EN 1815 Y TRANSPORTADAS POR EL ALCIDES AL PUERTO DE CÁDIZ: ${ }^{13}$

\begin{tabular}{|l|l|r|r|}
\hline \multicolumn{1}{|c|}{ COMPRADOR } & \multicolumn{1}{c|}{ CONSIGNATARIO } & CARGAS & REALES PLATA \\
\hline Josefa Bejarano & Juan Matías de Vertiz & $1.000,00$ & 78.000 \\
\hline Martín de Icaza & Tomás de Urrutia & $2.000,00$ & 156.000 \\
\hline Martín Revilla & Martín Revilla & 202,52 & 15.808 \\
\hline Juan Santos de Murrieta & Juan Santos de Murrieta & 202,52 & 15.808 \\
\hline Martín de Aramburu & José Antonio y Mariano Aramburu & 500,00 & 39.000 \\
\hline Vda. de Ruiz e hijo Terry & Vda. de Ruiz e hijo Terry & $1.608,66$ & 125.490 \\
\hline \multicolumn{1}{|c|}{ TOTAL } & & $5.513,70$ & 430.106 \\
\hline
\end{tabular}

12 Mazzeo, 1999a, 1-15.

13 Sobordo del Alcides, Lima, octubre de 1815, AFC. 
En una carta escrita por el comerciante Francisco María de Zuloaga desde el puerto del Callao a Francisco de Carranza le informaba de la salida el 1 de diciembre de 1815 de este puerto rumbo a Cádiz del barco El Águila y que en fechas próximas saldrían La Mariana y las fragatas Comercio y Minerva que, procedentes de Guayaquil, se les esperaba para el día 25 de ese mes cargadas con cacao. Del mismo modo Zuloaga aseguraba que el barco fletado por Arismendi, La Reina de los Ángeles, saldría en enero de 1816 y que a estos le seguirían El Catita y La Warren. Estos cinco últimos buques «transportarán de 36.000 a 40.000 arrobas de cacao y tras su marcha no quedaría barco alguno en El Callao. El precio de la arroba de cacao en Guayaquil se mantuvo de 4 a $4 \frac{1}{2}$ pesos». ${ }^{14}$ Ante la posible saturación del mercado de Cádiz por una llegada masiva de cacao que produciría una importante bajada de los precios, Carranza ordena que el dinero que le debe Zuloaga se lo mande en dinero y no en frutos.

La cascarilla, también llamada quina aromática, fue también uno de los productos más requeridos en Europa por su valor curativo y antitérmico. Esta planta se extraía principalmente en Cuenca y Piura y en menor grado en Yungo, Huánuco y Tarma. El precio de la arroba de cascarilla en Lima se mantuvo entre los 4 y 6 pesos, con un flete fluctuante que llegó a costar incluso el doble en periodo de guerra. A modo de ejemplo en periodo de paz se cobraba 36 reales por arroba y en guerra su valor ascendía hasta los 72 reales. En 1817 se exportaron 1.539 arrobas.

El poderoso comerciante Francisco Xavier de Izcue remitió a Francisco de Carranza la factura de 41 cajas de cascarilla embarcadas en la fragata Nuestra Señora del Carmen, alias Resolución, con destino a Cádiz a la consignación de su maestre Juan de Abajas y en caso de ausencia a los señores Marcelo Polanco y Olaguer Reynals, que dieron un peso de 628,7 arrobas por un valor de 6.651 pesos. ${ }^{15}$

Finalmente otros productos menos importantes eran comercializados en la península, tales como el cobre y el estaño, que en 1817 se exportaron 10.488 quintales del primero y 2.263 del segundo. Tal y como señala Mazzeo, en los años en que la salida de plata y oro decaía se producía un aumento de estos dos minerales. ${ }^{16}$ $1815, \mathrm{AFC}$

14 Carta de Francisco María de Zuloaga a Francisco de Carranza, Lima, 15 de diciembre de

15 Factura de Francisco Xavier de Izcue a Francisco de Carranza, Lima 20 de marzo de 1815, AFC.

16 Mazzeo, 1999b, 127-145. 


\section{Tiempos difíciles para el comercio gaditano al Perú}

Aunque el transporte marítimo se había reactivado tras la guerra napoleónica a partir de 1816 el acoso de buques al servicio de Buenos Aires y de Chile estranguló casi hasta asfixiar el libre tránsito de mercancías por mar. Corsarios como el británico Willliam Brown, que al mando de cuatro buques bloqueó y bombardeó el puerto del Callao capturando dos embarcaciones que entraban en el puerto, crearon el pánico entre la atemorizada población limeña. Una de estas dos naves, la fragata Consecuencia, transportaba seis tercios y un cajón arpillado asegurados en Cádiz por Juan de Abajas en el concepto de 4.000 pesos al 5,5\% y propiedad de Antonio Sáenz de Tejada. La crisis ya hacía mella en el comercio peruano y por esta razón Tejada le impartía a Abajas instrucciones muy precisas de las mercancías con alta demanda en el virreinato para que se las remitiera, como creas y entre anchas de Hamburgo que

sean bien tupidas y con bastante grano, pero sin el lustre con que suelen venir algunas por la goma y mucha prensa que se les dan; renglón a que me inclino por el pronto por ser de pobres, y que en todo tiempo, cuando no deje utilidad, tampoco mucho quebranto. ${ }^{17}$

Las noticias de apresamientos de barcos españoles por los innumerables corsarios de distintas nacionalidades (ingleses, franceses, sardos, rusos, norteamericanos y de las nuevas naciones americanas) convirtieron la navegación, prácticamente desde su salida de puertos españoles hasta sus destinos en América, en una actividad de alto riesgo. Zuloaga notificaba a Carranza el apresamiento de algunos buques a la altura de Río de Janeiro por los corsarios del Río de la Plata y lo sucedido a dos fragatas y un bergantín que sufrieron la misma suerte sobre la Isla de San Lorenzo a mediados de enero. A pesar de las dificultades que soportaba el consulado de comerciantes de Lima, se procedió a artillar las fragatas Tagle, Comercio, Reina de los Ángeles, Minerva, Palafox y el bergantín Europa con el fin de navegar hasta San Gallán en búsqueda de los corsarios que habían capturado las dos embarcaciones citadas. ${ }^{18} \mathrm{El}$ coste de la operación ascendió a la nada desdeñable cantidad de 160.000 pesos, medida que se extendió poco

17 Carta de Antonio Sáenz de Tejada a Juan de Abajas, Lima, 15 de junio de 1816, AFC. 1816, AFC.

18 Carta de Francisco María de Zuloaga a Francisco de Carranza, Lima, 26 de abril de 
después al acondicionar y armar el barco correo Abascal para que navegase de cabotaje y diera aviso a las naves españolas que se acercaban al puerto limeño. Finalmente el costo final de armar y mantener la flota durante esta acción costó al consulado 383.293 pesos. Varios meses después el virrey Pezuela solicitó al consulado que armara otras dos naves, la fragata Veloz Pasajera y el bergantín Pezuela, que durante el año que estuvieron de servicio su mantenimiento ascendió a otros 243.177 pesos.

La venta de los productos procedentes de España no resultaba nada fácil, debido a factores como el citado corso, la profunda descapitalización que padecía el virreinato y, sobre todo, por el colapso de mercancías procedentes de Panamá y Jamaica que inundaron los mercados peruanos. De este modo lo manifestaba Francisco María de Zuloaga al anunciar que ningún comerciante se había acercado a Lima procedente de la Sierra, Chile, Trujillo, Guayaquil, Cuenca, Quito, etc. por temor a sufrir algún peligro y «estamos sin saber a quién vender y atorándonos de Panamá». ${ }^{19}$ Otro ejemplo lo observamos en las impresiones que Juan de Abajas manifestó a su tío Francisco de Carranza de que no había encontrado quien quisiera entrar en el total del negocio que trajo en su expedición a excepción de un comerciante que tan solo le ofreció 350.000 pesos pagaderos en plazos largos. En vista de la imposibilidad de vender la mercancía, Abajas trató de hacerlo por partes o renglones según se presentase la ocasión, vendiendo cerca de 300.000 pesos, parte al contado y el resto a plazos, a «personas de moral seguridad». Entre las prendas que Abajas logró colocar destacan:

camisas con plazo a 59 pesos la docena y gracias pues se están vendiendo muchos efectos a menos de los principales de esa. Los efectos que he traído a mi cargo han sido renglones de mucha consideración sin surtimiento y con un terrible sobrecargo, como que fueron comprados a cambio de cacao. ${ }^{20}$

Recientes investigaciones nos desvelan que, a pesar de la victoria insurgente en Chacabuco en 1817, el intercambio de azúcar peruano por trigo chileno no llegó a desaparecer. ${ }^{21}$ Del mismo modo podemos decir que aunque la pérdida de Guayaquil y Trujillo suspendió el comercio lícito con la capital, este fue sustituido por un intenso y lucrativo contrabando. ${ }^{22}$ 1817, AFC.

19 Carta de Francisco María de Zuloaga a Francisco de Carranza, Lima, 10 de febrero de

20 Carta de Juan de Abajas a Francisco de Abajas, Lima, 24 de septiembre de 1816, AFC.

21 Mazzeo, 2007, 446.

22 Mazzeo, 2003, 221-223 


\section{Jamaica, la vía inglesa del comercio del Pacífico Sur}

La ausencia de barcos de guerra españoles en la región permitió a Inglaterra controlar las remesas de oro y plata con las que los comerciantes peruanos pretendían activar sus intercambios mercantiles. De este modo el corredor Panamá, Jamaica, Londres ocupará la mayor parte de la salida de caudales con destino a la capital británica. Allí la plata será cambiada a libras, parte se depositarán en las más importantes casas de comercio londinenses y el resto será enviado a España en letras de cambio.

La correspondencia entre Juan de Abajas y su tío Francisco de Carranza nos desvela cómo se produjo este comercio con Jamaica. El primero le notificaba que Manuel de Bárcena, comerciante y paisano, tenía previsto salir rumbo a Jamaica en la fragata Cazadora para colocar en Londres una remesa de 24.000 pesos de plata propiedad de Francisco María de Zuloaga:

Creo habrá muchos que hagan esta operación [... y] temo se dificulten las seguras libranzas contra Londres en donde son preferibles las que da el Almirante contra el Banco. Ustedes sin duda ignoran haberse impuesto nuevamente en Panamá un $4 \%$ a la plata que salga para Jamaica que es decir paga $14 \%$ en lugar del 10 que antes exigían. ${ }^{23}$

El 10 de marzo de 1817 la fragata Cazadora zarpó rumbo a Panamá. En este puerto se desembarcó la carga para ser transportada en mulas hasta Cruces, en donde era embarcada en canoas hasta el puerto de Chagres. Allí se trasbordó a la goleta Alexandra hasta el populoso Portobelo en donde el navío inglés Saliburg transportó la plata hasta Kingston. En la isla caribeña los caudales fueron embarcados en la fragata de guerra Ynconstand quien la trasladó hasta Londres. En la capital del Támesis, Manuel Bárcenas entregó la plata al consignatario Pedro Casimir Timerman y en ausencia del anterior se harían cargo los señores Fartet Lacosta y Cía. Abajas escribía que el citado Bárcenas:

trate de poner el líquido de esta cantidad en poder de usted bien sea tomando libranzas del Gobierno de Jamaica contra ese Banco y a favor de vuestra merced o remitiendo los pesos por el conducto más seguro y pronto que se presente. ${ }^{24}$

23 Carta de Juan de Abajas a Francisco de Carranza, Lima, 14 de febrero de 1817, AFC.

24 Carta de Juan de Abajas a Pedro Casimir Timerman, Lima, 10 de marzo de 1817, AFC. 
Timerman anunciaba a Francisco de Carranza la recepción de la plata remesada y se ponía a su disposición para terminar esta operación mercantil:

Respecto a cuyas partidas aguardo las órdenes que tenga usted por conveniente dirigirme. Según la resulta del caudal conducido por esta fragata y del que se aguarda por momentos en seguida con la fragata Active, se presenta en este instante nuestra plaza, juzgo que será muy prudente no manifestar empeño alguno por realizar aprisa los intereses de la parte de él que haya de retornarse en letras a España. ${ }^{25}$

La preciada plata americana era codiciada por todas las naciones y máxime en unos años en que las colonias se habían desmonetizado hasta tal punto que incluso se ofrecían interesantes cambios de moneda con tal de hacerse con esta savia del comercio ultramarino.

En el siguiente texto podemos leer cómo algunos maestres de los buques encargados de trasladar la plata a Europa eran seducidos por suculentas comisiones si despachaban la plata en donde se lo solicitasen. Del siguiente modo Francisco de Carranza se quejaba airadamente a su amigo y paisano Francisco Xavier de Izcue de la actitud del maestre de la fragata Carlota quien procedió de manera ilegal al desembarcar todo el oro y plata que tenía registrado en ese barco en Bahía de Todos Santos (Brasil) sin tener en cuenta la voluntad de sus dueños:

el registro de plata del que bajados $12 \frac{1}{2} \%$ lo negoció con aquel Banco Portugués a razón de 800 reis por cada peso, cuya operación a mi entender no justa, da quebranto a los interesados, quienes están en libertad de disponer cada uno de por sí de sus interés registrado por la vía que puedan, y como les acomode; pero el maestre no tuvo presente el derecho de extracción que tiene que pagar pues no lo bajó, y queda comprometido con la Real Hacienda para cancelación de su registro. ${ }^{26}$

Asimismo, a la saturación del comercio limeño con mercancías procedentes de Panamá hubo que sumar el creciente arribo de buques extranjeros de permiso que dieron el golpe de gracia al comercio hispanoperuano. El rico comerciante limeño Antonio Sáenz de Tejada era testigo de los «muchos algodones, y otros renglones que entran de Panamá» y de cómo

una fragata inglesa con permiso, cargada de efectos; y dos rusas, según se dice con cera, lonas, brines, jarcia y otras cosas más productivas del Norte: razón por lo que las platillas reales, bretañas, creas y demás lencería de Hamburgo, y otros muchos

25 Carta de Pedro Casimir Timerman, Londres, 2 de septiembre de 1817, AFC.

26 Carta de Francisco de Carranza a Francisco Xavier de Izcue, Cádiz, 28 de abril de 1817, AFC. 
géneros abundan y se vende a los precios con que no se costean los mismos renglones que viene de esa Península. ${ }^{27}$

La percepción de la decadencia del comercio limeño también era compartida por el ya citado Francisco Xavier de Izcue, yerno del anterior y uno de los grandes comerciantes del virreinato, cuando se quejaba de:

La llegada de una fragata procedente de Baltimore con permiso de la casa Smith y la venida de la fragata nombrada Infante D. Carlos procedente de Calcuta han hecho rebajar los lienzos a precios ínfimos a que se agrega la continua introducción por la vía de Panamá de toda clase de efectos. ${ }^{28}$

En 1818, la expedición que se hallaba embarcada y pronta a dar la vela bajo la escolta de la fragata de guerra María Isabel (su comandante el capitán de navío de la real armada D. Manuel del Castillo) estaba formado por las embarcaciones La Jerezana, Dolores, Magdalena, Elena (capturadas en la batalla de Talcahuano los días 28 y 29 de octubre de 1818), Todos los Santos (que debido a una vía de agua tuvo que anclar en Tenerife), $L a$ Trinidad (que se quedó en Buenos Aires) y la Especulación, Atocha, Santa María, Esmeralda (fragata de guerra) que llegaron al Callao durante 1818. Estos buques transportaban a dos batallones del regimiento Cantabria, el cuerpo de cazadores dragones y una compañía de zapadores.

A partir de 1820 las cartas que enviaba Carranza a Lima fueron embarcadas en fragatas inglesas de permiso, tales como La Mary, Lord Suffield, Eduardo, Hélice (estas dos últimas retenidas a la entrada del Callao por Cochrane). Los buques Comercio, Primorosa Mariana y Vigarrena suspendieron en junio de 1820 su salida para El Callao debido a la epidemia de fiebre tifus que asolaba la ciudad de Cádiz y asimismo por la insurrección del coronel Riego en Las Cabezas de San Juan en enero de ese mismo año.

\section{Segundo periodo: 1821-1826}

La esperanza de reconquista de la capitanía general de Chile que el virrey Pezuela había depositado en el brigadier Osorio se vio truncada de forma definitiva tras su derrota en la batalla de Maipú en 1818, por lo que

27 Carta de Antonio Sáenz de Tejada a Francisco de Carranza, Lima, 10 de mayo de 1817, AFC.

28 Carta de Francisco Xavier de Izcue a Francisco de Carranza, Lima, 1 de agosto de 1817, AFC. 
no se pudo restablecer el vital comercio legal entre los puertos del Callao y Valparaíso.

Tras esta pérdida, el consulado de comerciantes de Lima presentó un memorial al ministro de Hacienda Martín Garay para informarle de primera mano del estado lamentable que sufría el comercio peruano. Este documento criticaba la política liberal que la Junta Central había permitido a partir de 1809 a las naciones amigas, y más concretamente a Inglaterra, el comercio que a través del istmo de Panamá y con origen en la isla de Jamaica, inundaba con sus productos de bajo coste el mercado del Pacífico americano y la actitud pasiva de las autoridades virreinales al permitir durante años el contrabando que llevaban a efecto naves francesas, angloamericanas, inglesas y rusas. La respuesta del gobierno español no tardó en producirse y tras agradecer el patriotismo demostrado por el consulado, denegó su solicitud de cerrar los puertos españoles a los productos de naciones neutrales hasta que la maltrecha industria española se recompusiera. ${ }^{29}$

El año siguiente a esta derrota española no pudo ser más nefasta para los intereses de los comerciantes limeños. Si introducir legalmente sus productos procedentes de la península resultaba prácticamente imposible, más difícil lo fue con la llegada al Callao de cuatro buques ingleses con permiso:

los ingleses a nombre de ellos [los insurgentes de Chile y Buenos Aires] nos afligen solicitando el comercio libre con lo que este gobierno nos saca el corazón en términos que nos llegará a precipitar: Tiene concedido permiso a 4 buques ingleses para que descarguen el resto de sus cargamentos, que será valor de esta de 800 [mil] a un millón de pesos, habiendo descargado antes clandestinamente más de medio millón, llevándose su importancia en plata sellada y piña, en la corbeta Blosson. ${ }^{30}$

Pezuela apostó por conceder permiso durante un periodo de dos años a los comerciantes ingleses pensando que con esta medida se cargaría con un $30 \%$ los productos desembarcados que irían directamente a las arcas reales, además del $12 \%$ sobre los derechos comunes. Aunque Hamnett ${ }^{31}$ señala que esta polémica medida provocó la división de los realistas peruanos al posicionarse a favor de ella el Ayuntamiento y los exportadores limeños, deseosos de vender su azúcar, mientras que los comerciantes peninsulares rechazaban frontalmente esta injerencia extranjera, la realidad se nos presenta

29 Expediente del consulado de Lima sobre el deplorable estado de aquel comercio, Lima, 3 de mayo de 1817, Archivo General de Indias (AGI), Indiferente General, 2440, Consejo en sala segunda. 1819, AFC

30 Carta de Francisco Xavier de Izcue a Francisco de Carranza, Lima, 12 de febrero de

31 Hamnett, 1978,134-135. 
más compleja ya que pesaban más los intereses particulares que gremiales. Un ejemplo lo podemos ver cuando en 1818 los comerciantes ultramarinos Martín José Pérez de Cortiguera y Juan Abajas votaron en contra de la decisión del consulado de comerciantes de Lima de impedir el libre comercio con neutrales ya que en esos momentos lo que a estos comerciantes les urgía era poder sacar el capital obtenido de sus ventas. ${ }^{32}$ A finales del año siguiente, en diciembre de 1819, los españoles José de Arizmendi y Pedro de Abadía obtuvieron una licencia para introducir por el puerto del Callao artículos europeos y asiáticos por un monto de 150.000 pesos a cambio de entregar a la Real Hacienda una tercera parte. Pocos meses después Arizmendi volvió a obtener otro permiso, esta vez para la introducción de mercancías procedentes de los Estados Unidos por un valor de 50.000 pesos pagando los mismos impuestos que si fuesen productos españoles procedentes de Cádiz. Posteriormente este privilegio lo obtuvieron los vascos Murrieta y Lizarazuy ${ }^{33}$ para comprar telas que serían importadas al Perú procedentes de Río de Janeiro para su venta por un valor de 348.000 pesos y el pago de los mismos derechos aduanales impuestos a los productos procedentes de Panamá aportando para ello 100.000 pesos a las arcas reales. ${ }^{34}$

Para Izcue el comercio marítimo entre Cádiz y Lima resultaba una empresa abocada al fracaso más absoluto:

Tengo lástima a los que hayan remitido buque y efectos para el Callao, precisamente han de ser sacrificados: con estos acontecimientos nada se vende, ha desaparecido la confianza enteramente, y el clamor del comercio es grande. De la ancheta ${ }^{35}$ que de mi cuenta me remitió usted en el San Antonio y Xaviera, nada he vendido y ahora menos. ${ }^{36}$

La actividad corsaria no cesó durante este año e incluso la fragata Castilla que navegaba rumbo a Cádiz fue capturada. En ella viajaba el citado Juan de Abajas quien vio cómo era despojado de todos sus bienes dejándole tan solo la ropa que vestía. «Los corsarios cruzan nuestras costa y tiene paralizada nuestra navegación y la están haciendo los extranjeros que son nuestra ruina», escribía apesadumbrado Izcue. ${ }^{37}$

32 Parras, 1995, 129-132.

33 Idem, 146.

34 Flores Guzmán, 2001, 170.

35 Ancheta: 1. Porción corta de mercancías que alguien lleva a vender a cualquier parte. 2 Pacotilla de venta que se llevaba a América en tiempo de la dominación española. Diccionario de la Real Academia de la Lengua Española

36 Flores Guzmán, 2001, 170.

37 Carta de Francisco Xavier de Izcue a Francisco de Carranza, Lima, 12 de febrero de 1819, AFC. 
El exvirrey Abascal fue claro cuando en junio de 1819 dio su parecer sobre esta medida a pregunta del ministro interino de Hacienda. Para el primer marqués de la Concordia Española del Perú, a los exportadores agrícolas tan solo les guiaba el ansia de vender su azúcar excedente en el mercado chileno. ${ }^{38}$ Asimismo no perdió la oportunidad de expresar su inquietud por el libre comercio en las costas peruanas al entender que

si se adoptase el comercio libre con los ingleses no solo por dos años sino por menos tiempo, pues no necesitan mucho para arruinar la industria del país... no parece difícil discurrir el partido que tomarían los 15-20 mil artesanos que en Lima viven de su trabajo, 5-6 mil de ellos milicianos hechos a manejar armas... ${ }^{39}$

La pronta aportación del consulado de Lima de medio millón de pesos al $6 \%$ de interés a pagar en mensualidades de 100.000 pesos, así como la entrega de otros 200.000 pesos al contado en el mes de octubre y el compromiso de aportar a la corona 117.000 pesos mensuales, obligó a revocar el acuerdo con Inglaterra. Finalmente para el año 1820 la cantidad final entregada por el consulado a las arcas reales desde principios de siglo alcanzaría la impresionante cifra de 7.306.244 pesos. ${ }^{40}$

Aunque Pezuela no aprobó el libre comercio con neutrales, siguió concediendo permiso a barcos de distintas banderas. Izcue manifestaba su pesar por estas licencias y así se lo manifestaba a su amigo Carranza a finales de 1820:

Este gobierno ha concedido seis permisos para los puntos que quieran pedir, coincidiendo la internación de toda clase de efectos, sin reservar Calcuta, Cantón, Janeiro, Londres y Estados Unidos; con tal que le adelanten dinero a cuenta de los derechos que han de adeudar en su internación de modo que ese comercio debe olvidarse de este punto, por año y medio contados desde esta fecha a excepción de papel, fierro, vino Cantón y algunos renglones peculiares a ese suelo. ${ }^{41}$

Sobre esa misma fecha se llevó a cabo una contratación con la fragata inglesa ballenera Apost para la compra de 4.000 fusiles, pistolas y sables de Inglaterra o Francia y la autorización de ingresar efectos extranjeros por valor de 200.000 pesos, los cuales pagarían a su entrada aranceles como si vinieran de Cádiz. ${ }^{42}$

38 Flores Guzmán, 2001, 162.

39 Marqués de la Concordia al ministro interino de Hacienda, Madrid, 29 de junio de 1819, AGI, Lima 1550.

40 Mazzeo, 2003,199-203.

41 Carta de Francisco Xavier de Izcue a Francisco de Carranza, Lima, 22 de diciembre de 1820, AFC.

42 Mazzeo, 2010, 267-281. 
Los barcos ingleses ${ }^{43}$ aprovecharon la falta de buques de guerra españoles en el área para portar en sus bodegas miles de pesos con destino a Inglaterra u otro puerto en donde ganarían en el cambio: «En la actualidad no hay buque de guerra español, pero se podrá acaso proporcionar registro en buque de guerra neutral para el Janeiro», señalaba Izcue. ${ }^{44}$ Finalmente el consulado de comerciantes limeños obtuvo del virrey permiso para abrir registro de caudales a la corbeta de SMB Tyne con destino a Portmouth con escala en Río de Janeiro, con el pago del $15 \%$ anticipado por todos los derechos reales y el $2 \%$ de flete a su llegada. ${ }^{45}$

El ejército libertador argentino-chileno desembarcó en Paracas en septiembre de 1820 y pronto las tropas realistas quedaron cercadas en la capital peruana. La actitud del virrey de no abandonar Lima, en contra del criterio de la mayor parte de su oficialidad que consideraba conveniente organizarse en la sierra (en donde los recursos eran más abundantes e impedían la continua deserción realista), provocará su destitución en enero de 1821 por el general La Serna. Este vacío permitió al general San Martín entrar en la capital limeña, donde encontró una población de más de 50.000 habitantes agotada de soportar a lo largo de los últimos años el peso de la defensa del virreinato. ${ }^{46}$

El 5 de julio de 1821 el general La Serna abandonaba la capital virreinal para dirigirse a la sierra en donde podría reconquistar el espacio perdido y derrotar finalmente a los independentistas. De todos era conocido que, ante el sitio que sufría Lima y el control del mar por Lord Cochrane, pocas posibilidades de supervivencia le quedaban al ejército realista si continuaba defendiendo una ciudad tan grande con tantos frentes abiertos que imposibilitaban su aprovisionamiento. La Serna trasladó a la fortaleza del Real Felipe en El Callao 900 soldados que no podían acompañar al cuerpo del ejército a la sierra por encontrarse enfermos con la esperanza de que tras su recuperación protegieran tan importante bastión. El general español delegó en los marqueses de Montemira y del Valle de Oselle la custodia de la ciudad hasta que llegaran las tropas de San Martín, hecho que se produjo cuatro días después. Hábilmente La Serna puso a disposición de la milicia limeña 200 fusiles para mantener el orden

43 Malamud, 2007, 42.

44 Carta de Francisco Xavier de Izcue a Francisco de Carranza, Lima, 22 de abril de 1820, AFC.

45 Idem.

46 Ruiz de Gordejuela, 2006b, 455-456. 
en la ciudad pero cantidad insuficiente como para emprender una acción armada contra los patriotas. ${ }^{47}$

Flores Galindo habla de cómo el temor a la inminente entrada de los patriotas provocó que gran parte de la aristocracia se refugiara en los cercanos castillos del Callao, en algún convento, iglesia e incluso en algún buque extranjero anclado en este puerto. Esta huida contagió a los temerosos españoles, en su mayor parte compuesta por pequeños comerciantes, propietarios y administradores que, asustados ante lo que ellos creían una inminente rebelión de la plebe y razia de los esclavos negros, abandonaron sus negocios y domicilios para refugiarse junto a sus familias en los castillos. Resulta paradójico que las casas y bienes de la aristocracia no sufrieron ningún daño siendo objeto de la ira popular los pequeños y medianos comercios peninsulares..$^{48}$

Una de las primeras medidas que aprobó el general San Martín tras su entrada en Lima fue la de proclamar la independencia del Perú, acta que fue firmada por menos de la mitad de los nobles titulados y solo una tercera parte de los miembros del Tribunal del Consulado. ${ }^{49}$ Entre los que no comulgaron con el nuevo régimen y que decidieron regresar a la península se encontraban al menos una quinta parte de los miembros del cabildo eclesiástico metropolitano, siete miembros peninsulares de la Audiencia así como otros altos funcionarios del virreinato. ${ }^{50}$ Importantes comerciantes españoles en el Perú como Félix D’Olhabarriaga Blanco, Andrés Sánchez Quirós o José Ventura Aguirre-Solarte ya habían emigrado a distintas plazas de Europa desde fechas previas a la independencia, cuando cientos de españoles abandonaron el Perú como consecuencia de la política antiespañola orquestada por el ministro Monteagudo. ${ }^{51}$ Muchos de estos emigrados decidieron instalarse en Londres o Burdeos, en donde llegaron a gestionar

47 Anna, 2003, 234.

48 Flores Galindo, 1984, 216-217.

49 Ruiz de Gordejuela, 2006b, 454.

50 Rizo-Patrón, 2001, 414-415.

51 Relación de comerciantes emigrados, Lima, 15 de marzo de 1822, AGI, Indiferente, 1571. Manuel Gorbea, Cristóbal Murrieta, José Ramírez, Francisco Saldicaray, M. Barrena, Juan Bautista Aguirre, Domingo Urquijo, Manuel Ortiz Villalta, Ignacio Necochea, Manuel Ugarte, Ramón Villa, D.M. Irribarren, Juan Ignacio Mendizábal, Juan Matías Echavarri, Nicolás de Carmineaga, Francisco Necochea, Miguel Antonio Cerda, Cayetano Rubio, Pedro Moreno, Manuel Posadillo, Juan Gil, José Valdez, Manuel Melitón del Valle, Francisco Quiroz, Pedro Primo, Martín Aramburu, Francisco de la Bárcena, José Agustín Lizarralde, Francisco Iñarra, José San Martín, Amador Gallo, José Isasi, Dionisio Farfán, Fernando del Maso, Manuel Baruna, José de la Rosa, Juan Bautista Aguirre, José García, Miguel Gárate, Francisco Arellano, Cayetano Diles, Juan Elguera, M. Barrena, José Barinaga, Manuel Ortiz Villalta, Faustino del Campo, José Salgado, Fulgencio Zavala y Fco. María Zuloaga. 
el comercio y la llegada de caudales americanos, hecho que inquietó a los comerciantes bordeleses, que veían cómo la plata que llegaba no era precisamente como resultado de sus empresas comerciales en el continente americano, sino más bien de los ahorros de los expulsos americanos..$^{52}$

La Junta de Comercio, con la totalidad de sus miembros, debió resolver la petición urgente del nuevo gobierno de un préstamo de 150.000 pesos sobre los derechos de aduana. Ante la imposibilidad de que los ricos comerciantes pudieran sufragarlo se optó por ampliar la convocatoria al resto de vecinos de Lima. ${ }^{53} \mathrm{El}$ comerciante que mayor cantidad aportó resultó ser Francisco Xavier Izcue, quien se comprometió a donar 4.000 pesos, aunque la cantidad final que entregó fue poco más de la mitad de lo prometido (2.666 pesos)..$^{54}$

Para solventar la guerra, el 12 de abril de 1822 San Martín aprobó el comercio libre únicamente por los puertos del Callao y Huanchaco de buques de todas las banderas bajo el pago de un $20 \%$ sobre todos los géneros que ingresaran en buque extranjero, el $18 \%$ sobre los productos que llegasen en buques de Chile, Río de la Plata y Colombia y el $16 \%$ si se trataban de buques peruanos. Además abolió las aduanas interiores y permitió la circulación de mercancías sin necesidad de guías. El oro y la plata debían pagar por su extracción, cualquiera que fuese la bandera de la embarcación, el $5 \%$ por la plata y el $2,5 \%$ por el oro; además quedaba prohibida la extracción de dichos minerales no acuñados. En cuanto a los productos que saliesen en buques extranjeros, habrían de pagar el $4 \%$, y el $3,5 \%$ y si lo hacían en buques con bandera de Chile, Río de la Plata y Colombia, pagarían solo el $3 \% .55$

De esta manera se ponía en funcionamiento el primer reglamento de comercio de la época republicana, que establecía, más que un comercio libre, un comercio «protegido» que imponía aranceles escalonados para favorecer a los países americanos. Esta circunstancia permitió que muchas embarcaciones inglesas se «americanizasen» al enarbolar la bandera peruana antes de entrar a puerto para recibir mayores franquicias. ${ }^{56}$

52 Ruiz de Gordejuela, 2006b, 174.

53 Villa, 1999, 168. También en Colección de documentos para la Historia de la Independencia del Perú, Lima, Comisión Nacional del Sesquicentenario de la Independencia del Perú, 1970, vol. I, t. VII, 219.

54 Mazzeo, 2010, 281. Informes y oficios del Tribunal del Consulado.

55 Ibidem, 282.

56 Mazzeo, 2003, 221. 
A pesar de las enormes dificultades que padecían los peninsulares para ejercer el comercio, estos continuaban buscando otras vías para poder vender sus mercancías. Izcue no descansaba en sus proyectos comerciales e instaba a su viejo amigo Carranza a que le procurase enviar, vía Gibraltar, efectos que escaseaban en Lima. Izcue, que se acababa de naturalizar peruano, no quería quedarse fuera de los negocios de importación por lo que dio órdenes a Carranza para que comprara mercancías por valor de 10 a 15.000 pesos y que estas fueran embarcadas en algún navío inglés o norteamericano y que cuyo capitán se hiciera responsable de la carga y de su consignación. ${ }^{57}$

En una carta posterior el mismo Izcue describe un panorama desolador para los comerciantes limeños cuando dice que:

el numerario escasea mucho: el papel moneda está perdiendo de 18 a $20 \%$. La salida del dinero en lugar de pagar $5 \%$ en lo sucesivo pagará $7 \%$ y el oro $3 \%$ se está haciendo mucho reglamento y se prohíben todas cosas hechas de ropa blanca y de color, muebles de todas clases, jabón, etc. ${ }^{58}$

En 1823 la fragata inglesa Amanda desembarcó en los puertos peruanos mercancía por valor de 800.000 pesos y obtuvo la extracción libre de derechos de 3.000 quintales de cacao (299.700 libras esterlinas). A la cabeza de este negocio con el gobierno republicano se encontraban los comerciantes ingleses Juan Begg, Guillermo Hodgson, Guillermo Cochrane, Estalisnao Lynch, Juan Parish Roberson y José Priglos, y el español Manuel Castilla, quienes hicieron entrega de 70.000 pesos al contado, 120.000 pesos pagaderos en tres mensualidades, 20.000 a entregar en el plazo de un mes y los 40.000 restantes en dos meses.

Cádiz dejó de ser destino de las exportaciones del continente americano y los comerciantes españoles en el Perú vieron cómo desaparecían sus nexos políticos y comerciales con la metrópoli. De este modo el prestigio y poder ya no emanaban del reconocimiento de la corona, y al romperse este lazo secular se abría paso a una nueva etapa de enorme dificultad. ${ }^{59}$

A pesar de la profunda crisis, desde 1820 Francisco Xavier de Izcue continuó con su comercio oceánico pero, en vez de hacerlo con apoderados españoles y desde Cádiz, lo realizó desde Gibraltar y con apoderados

57 Carta de Francisco Xavier de Izcue a Francisco de Carranza, Lima, 30 de noviembre de 1822, AFC.

58 Carta de Francisco Xavier de Izcue a Francisco de Carranza, Lima, 14 de diciembre de 1822, AFC.

59 Ruiz de Gordejuela, 2006b, 467. 
ingleses como James Giró y Carlos G. Suett. Pero esta política comercial no sería ejercida solo por Izcue. Su paisano Santiago de Goyeneche viajó en la fragata americana Brown desde Gibraltar al Callao, con escala en Intermedios, transportando ancheta propia y por comisión de terceros. A este le acompañaba su socio Carlos Olivares, quien para Carranza era un «paisano honrado y merecedor de mejor suerte que tendría mucha satisfacción la lograse en ese país con el favor de los amigos, entre quienes cuento a usted como primero para que consiga su objeto». ${ }^{60}$ Otro ejemplo lo tenemos en el viaje de la fragata norteamericana India, que zarpó el 5 de diciembre de 1824 del puerto de Gibraltar rumbo a los puertos peruanos. En esta embarcación viajaron Samuel Robert y el joven Felipe González (sobrino de Francisco de Carranza y primo de Juan de Abajas). Este último, decía su tío, «posee el francés y lleva de aquí ya rudimentos del idioma inglés que si el tiempo los detiene en Gibraltar llegará al destino con el idioma en el cuerpo». Carranza entendió claramente que el nuevo comercio exigía de nuevos y preparados comerciantes, en donde el dominio de idiomas resultaba vital para poder hacerse un hueco en este nuevo orden mercantil: «He visto que para andar por el mundo es necesario tratar con individuos de dichas dos naciones». ${ }^{61}$

Para los peninsulares que permanecieron en Lima, las derrotas españolas en las batallas de Junín y Ayacucho en diciembre de 1824, y la inminente entrada de las tropas patriotas en la ciudad, provocaron que muchos de los españoles y limeños que habían sido afines a la corona se refugiaran en las fortalezas del Callao, en donde 2.000 soldados realistas a cuyo mando se encontraba el brigadier Rodil resistirán hasta enero de 1826 cuando la hambruna y las enfermedades aniquilarán a un número no determinado de realistas, cifra que pudiera variar, según los investigadores, entre los 3.000 y los 6.000 fallecidos, sobreviviendo tan solo 700 de los sitiados. En palabras del comerciante Felipe González:

Muchísima ha sido la mortandad que ha habido por hambre en la población del Callao: en el bien entendido entre ella y Castillos componían desde un principio de 6 a 7 mil almas de todas clases y edades; y los que han sobrevivido a tantas angustias y privaciones, etc. es de un corto número. ${ }^{62}$

60 Carta de Francisco de Carranza a Francisco Xavier de Izcue, Cádiz, 27 de septiembre de 1824, AFC.

61 Carta de Francisco de Carranza a José Joaquín de Aguirre, Cádiz, 10 de diciembre de 1824, AFC.

62 Carta de Felipe González a Francisco de Carranza, Guayaquil, 15 de febrero de 1826, AFC. 
González pudo conocer de primera mano cómo los efectos del sitio habían provocado la desaparición de los pocos comerciantes peninsulares que aún permanecían en el Perú:

Murió Elizalde, Tellería, D. Ignacio González, D. Víctor Angulo, D. José Francisco de Isasi en el castillo de Callao. D. José Lasarte está bastante enfermo, Idiáquez, Santo Domingo Celayeta y algunos otros pocos como Salguero, Zalduendo también están encerrados en las fortalezas con bastante incomodidad. ${ }^{63}$

Cuatro días antes de que Rodil entregara la plaza, el 19 de enero de 1826 fallecía entre sus muros, víctima del escorbuto, Francisco Xavier de Izcue. ${ }^{64}$

El papel protagónico de la elite comercial peruana se vio radicalmente anulado por el papel jugado por profesionales liberales; de hecho, en el Primer Congreso Constituyente sobre un total de 91 diputados tan solo se encontraban nueve comerciantes, nueve propietarios y tres mineros. A estos datos hay que añadir que el número de comerciantes registrados entre 1791 y 1826 pasó de 393 a 266 individuos. La llegada al poder de los insurgentes vino acompañada de la presencia de agentes comerciales ingleses, que destacaron por su giro mercantil en los primeros años independientes. Juan Beggs fue un importante importador de productos de consumo masivo que, en el período de 1821 a 1828 , ingresó un total de 68.551 pesos en telas provenientes de Liverpool, Valparaíso y Arica, además de otros productos de distintos puertos del Pacífico y Europa, por un valor de 153.172 pesos. Entre 1821 y 1822, Juan Parish Robertson importó 27.438 pesos en mercaderías; mientras que, por su parte, Templeman Bergman y Cía. lo hizo por 290.815 pesos entre 1825 y 1828 . Estos comerciantes eran reconocidos por el consulado de comercio como principales, dado que anualmente se les había calculado un giro mercantil de 120.000 pesos. ${ }^{65}$ Tal y como señala Flores Galindo, Inglaterra se convirtió en la nueva potencia hegemónica gracias a diversos factores determinantes como la destrucción

63 Carta de Felipe González a Francisco de Carranza, Guayaquil, 5 de agosto de 1825, AFC.

64 El navarro Francisco Xavier de Izcue, no solo obtuvo una carta de naturaleza para quedarse en el país en 1821, sino que fue cónsul del Tribunal de Comercio en varias ocasiones: 1811, 1812, 1813 y 1816. Dejó a su familia una herencia de 633.771 pesos fuertes. Su hijo Juan Francisco continuaría con sus negocios.

65 Mazzeo, 2010, 223-294. Razón del repartimiento hecho por este Consulado de acuerdo con sus consejeros y diputados a todos los comerciantes de esta ciudad «mayores y menores» con arreglo al supremo decreto de 4 del corriente, Lima, 1826, AGN, Aduana del Callao, Sección Mares del Sur, 1821-1829. 
de la flota mercante peruana, la quiebra del Tribunal del Consulado limeño y la profunda crisis económica que asolaba el virreinato. Esta situación provocará una cadena de quiebras mercantiles en Cádiz que debilitarán aún más el comercio ultramarino gaditano. ${ }^{66}$

Entre los muchos españoles que abandonaron el Perú, algunos continuaron negociando con la nueva nación gracias a una importante red de empleados, muchas veces familiares, que a lo largo del continente americano y de las principales plazas comerciales europeas trabajaban para ellos, tal como lo habían venido realizando con anterioridad. Años después, bien entrado el siglo XIX, solo unos pocos emigrados retornaron al Perú en donde habían dejado familia, amigos y propiedades. Respecto a estas últimas, muchas habían sido confiscadas por el gobierno independiente o enajenadas por sus administradores, por lo que les esperaban largos procesos judiciales para recuperarlas, aunque serán sus hijos y nietos los que lo conseguirán. ${ }^{67}$ A partir de 1835 empezamos a conocer españoles que pretenden emigrar al Perú para dedicarse al comercio aunque su número será muy limitado. ${ }^{68}$

\section{Conclusiones}

Los comerciantes gaditanos y limeños del primer cuarto de siglo XIX, en gran número vasconavarros, vivieron un periodo jalonado de dificultades de todo tipo. El contrabando, el pretendido libre comercio, las embarcaciones extranjeras con permiso de entrada de mercancías, la inexorable presencia británica y un corso que llegó a estrangular un paupérrimo flujo naval entre los puertos de Cádiz y El Callao hicieron que una impotente expotencia como la española claudicara y dejara al amparo de naciones extranjeras el comercio limeño.

Esta investigación nos permite concluir, entre otras cosas, que los hombres de negocios de ambas orillas no cejaron en su empeño por

66 Ruiz de Gordejuela, 2006a, 227. Entre las muchas compañías que quebraron podemos señalar la producida en 1825 por los citados anteriormente Viuda de Ruiz e Hijo Terry (propietaria de la fragata Alcides).

67 Ruiz de Gordejuela, 2006b, 472.

68 Licencia de Juan Bautista Mendiola para viajar a Lima a casa de su hermano Martín para ayudarle en su comercio, Bilbao, 25 de mayo de 1835, Archivo Foral de Bizkaia (AFB), Administración de Bizkaia, Seguridad Pública, AQ00279008 (también en AQ00283/038). El vecino de Bilbao Valentín García viajó a Lima en 1839. 
mantener un negocio que ya manifestaba importantes limitaciones desde finales del siglo XVIII y que, como consecuencia de las numerosas guerras en las que España se vio involucrada, frenaron, incluso en ocasiones anularon, el comercio entre el virreinato del Perú y la península. Inglaterra, como principal embarcador, se posicionó en el primer lugar en esta carrera por el control del enorme mercado peruano-chileno utilizando la vía de Panamá y Jamaica para trasladar a su metrópoli los caudales de los comerciantes españoles que aún permanecían en el virreinato, unos para ser invertidos en nuevas negociaciones y otros para ser atesorados en bancos y casas de comercio de Londres.

A pesar del fuerte impacto de la guerra en las relaciones comerciales estas no se interrumpieron del todo, aunque los pocos comerciantes españoles que en los primeros años de la década de los años veinte aun se atrevieron a enviar sus mercancías al Perú lo hicieron principalmente en barcos y a consignatarios ingleses desde el puerto de Gibraltar.

En síntesis creemos demostrar que, a pesar de las enormes dificultades propias de un escenario en guerra, los comerciantes tanto peruanos como gaditanos buscaron distintos modos que les permitieran continuar con su secular comercio, por lo que podemos concluir que no se produjo una desaparición sino una costosa adaptación a los nuevos tiempos que permitieron el intercambio de mercancías entre estos dos destinos.

Recibido el 21 de enero de 2015 Segunda versión 3 de agosto de 2015 Aceptado el 11 de septiembre de 2015

\section{Referencias bibliográficas}

Anna, Timothy E., La caída del gobierno español el Perú. El dilema de la independencia, Lima, Instituto de Estudios Peruanos, 2003.

Bustos Rodríguez, Manuel, Cádiz en el sistema atlántico. La ciudad, sus comerciantes y la actividad mercantil, (1650-1830), Cádiz, Sílex Ediciones, 2005.

Flores Galindo, Alberto, «El militarismo y la dominación británica, 1825-1845», en Araníbar, Carlos, Nueva Historia General del Perú, Lima, Mosca Azul Editores, 1979, 107-121.

- Aristocracia y plebe, Lima, 1760-1830, Lima, Mosca Azul Editores, 1984.

Flores Guzmán, Ramiro, «El Tribunal del Consulado de Lima frente a la crisis del estado borbónico y la quiebra del sistema mercantil (179-1821)», en 
O’Phelan Godoy, Scarlett (comp.), La independencia del Perú. De los Borbones a Bolívar, Lima, Pontificia Universidad Católica del Perú, Instituto Riva-Agüero, 2001, 137-172.

García-Baquero González, Antonio, Comercio colonial y guerras revolucionarias. La decadencia económica de Cádiz a raíz de la emancipación americana, Sevilla, Escuela de Estudios Hispano-Americanos, CSIC, 1972.

Hamnett, Brian, Revolución y contrarrevolución en México y Perú: Liberalismo, realeza y separatismo (1800-1824), México, Fondo de Cultura Económica, 1978.

Malamud, Carlos D., «El fin del comercio colonial: Una compañía comercial gaditana del siglo XIX», Revista de Indias, 151-152, Madrid, 1978, 287-347.

- Sin marina, sin tesoro y casi sin soldados. La financiación de la reconquista de América, 1810-1826, Santiago de Chile, Centro de Estudios Bicentenario, 2007.

Mazzeo de Vivó, Cristina Ana, «El comercio internacional en la crisis de la independencia de América. Lima-Cádiz 1783-1825», en Mazzeo de Vivó, Cristina Ana et al., Los comerciantes limeños a fines del siglo XVIII. Capacidad y cohesión de una elite, 1750-1825, Lima, Pontificia Universidad Católica del Perú, 1999a, 1-15.

— «El comercio libre de 1778 y sus repercusiones en el mercado limeño» en O’Phelan Godoy, Scarlett (comp.), El Perú en el siglo XVIII. La Era Borbónica, Lima, Pontificia Universidad Católica del Perú, Instituto RivaAgüero, 1999b, 127-145.

- «El Consulado de Lima y la política comercial española frente a las coyunturas de cambio de fines del periodo colonial (1806-1821)», en Hausberger, Bernard e Ibarra, Antonio (eds.), Comercio y poder en América Colonial: los consulados de comerciantes, siglos XVII-XIX, Madrid, IberoamericanaVervuert, Instituto Mora, 2003, 199-223.

- «Los comerciantes, el Consulado y los préstamos al gobierno republicano Lima-Perú, 1820-1840», Revista Complutense de Historia de América, 32, Madrid, 2006, 63-84.

- «El circuito comercial del Pacífico. Convergencia y divergencia entre dos ciudades portuarias: El Callao y Valparaíso entre la colonia y la república», en Guerra Martinière, Margarita; Mazzeo de Vivó, Cristina y Rouillon Almeida, Denisse (eds.), Historias compartidas. Economía, sociedad y poder, siglos XVI-XX, Lima, Pontificia Universidad de Lima, Instituto RivaAgüero, 2007, 421-453.

- «El comercio colonial en el siglo XVIII y su transformación frente a las coyunturas de cambio», en Contreras, Carlos (ed.), Compendio de Historia económica del Perú. Vol. III. Economía del periodo colonial tardío, Lima, Banco Central de Reserva del Perú, Instituto de Estudios Peruanos, 2010, 223-294. 
O’Phelan Godoy, Scarlett, La independencia del Perú. De los Borbones a Bolívar: Lima, Pontificia Universidad Católica del Perú-Instituto Riva-Agüero, 2001.

Ortiz Sotelo, Jorge, Perú y Gran Bretaña: política y economía (1808-1839), a través de los informes navales británicos, Lima, Asociación de Historia Marítima y Naval Iberoamericana, Pontificia Universidad Católica del Perú, 2005.

Parrón Salas, Carmen, De las Reformas borbónicas: El Consulado y el comercio marítimo de Lima, 1778-1821, Murcia, Academia General del Aire, 1995.

Rizo-Patrón Boylan, Paul, «Las emigraciones de los súbditos realistas del Perú hacia España durante la crisis de la independencia», en O'Phelan Godoy, Scarlett (comp.), La independencia del Perú. De los Borbones a Bolívar, Lima, Universidad Pontificia Católica del Perú, 2001, 407-428.

Ruiz de Gordejuela Urquijo, Jesús, La Expulsión de españoles de México y su destino incierto, 1821-1836, Universidad de Sevilla, Diputación de Sevilla, Consejo Superior de Investigaciones Científicas, Madrid, 2006a.

- «La salida de la elite virreinal del Perú: sacerdotes, funcionarios y comerciantes, 1821-1825», Revista de Indias, vol. LXVI, 237, Madrid, 2006b, 453-472.

Turiso Sebastián, Jesús: «Los últimos comerciantes peninsulares en el Perú colonial: Los hermanos Elizalde», en Armillas Vicente, José A. (ed.), VII Congreso Internacional de Historia de América, Zaragoza, Gobierno de Aragón, 1998, v. 3, 1847-1858.

Villa Esteves, Deolinda Mercedes, «Liderazgo y poder: La elite comercial limeña entre el comercio libre y la guerra de independencia (El caso de Antonio Elizalde)», en Mazzeo de Vivó, Cristina Ana et al., Los comerciantes limeños a fines del siglo XVIII. Capacidad y cohesión de la elite 1750-1825, Lima, Pontificia Universidad Católica del Perú, 1999, 133-173. 


\section{Anexos}

\section{N. ${ }^{\circ}$ 1. DEPOSITARIOS QUE EMBARCARON PLATA Y ORO AL ALCIDES}

\begin{tabular}{|c|c|c|c|}
\hline $\begin{array}{l}\text { DEPOSITARIOS } \\
\text { (N. } .^{\circ} \text { de registros) }\end{array}$ & $\begin{array}{l}\text { PESOS } \\
\text { (Total } \\
\text { depositado) }\end{array}$ & $\begin{array}{l}\text { DEPOSITARIOS } \\
\text { (N. }{ }^{\circ} \text { de registros) }\end{array}$ & $\begin{array}{c}\text { PESOS } \\
\text { (Total } \\
\text { depositado) }\end{array}$ \\
\hline Martín José Pérez de Cortiguera (11) & $70.287,2$ & Rafael Peró (3) & 8.074 \\
\hline Francisco Xavier de Izcue (12) & 37.980 & Pedro Abadía (5) & $8.017,2$ \\
\hline Juan Bautista de Gárate (15) & $34.927,6$ & Manuel Martínez Gorriti (2) & 8.000 \\
\hline Francisco Carranza (3) & $30.532,8$ & Nicolás Iraola (7) & $7.380,9$ \\
\hline José Manuel de Ugarte (8) & $26.297,6$ & Manuel de Arrieta (3) & 7.502 \\
\hline Faustino del Campo (5) & $21.332,5$ & Miguel Gárate (3) & 6.981 \\
\hline Andrés Revoredo (10) & 19.820 & Fulgencio Antonio de Zabala (2) & 6.500 \\
\hline Juan Bautista de Valdeavellano (8) & 17.007 & José Antonio de Errea (3) & 6.461 \\
\hline Jacinto Jiménez y Herrán (5) & 14.600 & Martín de Aramburu (2) & 6.000 \\
\hline Juan Pedro de Celayeta (4) & 14.418 & Benito José Dorca (2) & 5.133 \\
\hline Antonio Merino Villanueva (5) & 13.000 & Dámaso Árias (5) & 4.767 \\
\hline Juan Bautista de Sarraoa (2) & 12.000 & Vicente Martínez (3) & 4.745 \\
\hline Luciano Murrieta (2) & 12.000 & Manuel Luciano López (3) & 4.000 \\
\hline Antonio y José Elizalde (8) & $11.669,4$ & Ambrosio Canicoba (4) & $3.634,9$ \\
\hline $\begin{array}{l}\text { Miguel Tomás de Alfaro y Miguel } \\
\text { Antonio de Vertiz (2) }\end{array}$ & 11.000 & Juan Hernández (6) & $2.735,6$ \\
\hline Santiago Martínez Rodríguez (12) & 10.621 & Martín de Osambela (3) & 2.556 \\
\hline Manuel Ortiz de Villate (3) & 10.263 & José Vicente de Jáuregui (3) & 2.538 \\
\hline Juan Macho y Hermano (2) & 10.000 & José Martínez Descalzo (3) & 1.500 \\
\hline Francisco María de Zuloaga (6) & $8.989,4$ & Martín de Guisasola (10) & 1.244 \\
\hline
\end{tabular}




\section{N. ${ }^{\circ}$ 2. PROPIETARIOS DE CAUDALES TRANSPORTADOS POR EL ALCIDES}

\begin{tabular}{|c|c|c|c|}
\hline PROPIETARIOS & PESOS & PROPIETARIOS & PESOS \\
\hline José Vea-Murguía & $43.004,6$ & Nicomedes Milanos & 6.500 \\
\hline Pedro Regalado del Campo & $20.617,1$ & Miguel de Gárate & 6.500 \\
\hline Manuel López Barajas & 20.228 & Juan Bautista Valdeavellano & $6.402,9$ \\
\hline José Xavier de Zuloaga & 20.100 & Juan Ranger & $6.395,2$ \\
\hline Juan Antonio Llorente & 14.500 & Sobrinos de Aguerrevere y Lostra & $6.013,4$ \\
\hline Luciano Murrieta & 12.000 & José Antonio de Albizuri & 6.000 \\
\hline José Joaquín de Aguirre & $10.603,4$ & Antonio de Villanueva & 6.000 \\
\hline Juan Antonio Aramburu & 10.500 & Manuel Antonio de los Ríos & 6.000 \\
\hline La Expedición (Vda. de Ruiz) & 10.000 & Junta de Reemplazos de Cádiz & 6.000 \\
\hline Luis Francisco de Gardeazabal & 10.000 & María Ana Compaino & $5.929,4$ \\
\hline Miguel de Jáuregi & 10.000 & Juan Pértica & 5.000 \\
\hline Andrés del Castillo & 10.000 & Vicente José de la Jara & 5.000 \\
\hline José Francisco y Pedro Portela & 10.000 & Paúl Larrieta y Cía. & $4.712,4$ \\
\hline Conde de San Javier & 10.000 & Sres. Armas y Llorente & 4.550 \\
\hline Francisco Xavier de Izcue & 9.000 & Nicolás Herrán & 4.480 \\
\hline Juan Matías de Vertiz & 9.000 & Juan Valdez & $4.246,2$ \\
\hline Miguel Blanco & 9.000 & Luis Gargollo & 4.000 \\
\hline Domingo de Vea & $8.624,4$ & Joaquín María Ferrer & 4.000 \\
\hline Tomás Urrutia & $7.245,4$ & Melchor de Sevilla & 4.000 \\
\hline José Alvaredo e Hijos & 7.000 & Manuel Martínez y Gorroti & 4.000 \\
\hline Manuel Micheo & 7.000 & Tomás Ruiz de Zorzano & 4.000 \\
\hline Sres. Quirós y Santo Domingo & 7.000 & Vicente Cabrera & 4.000 \\
\hline José Romero Campo & 6.600 & Pedro de Zulueta & 3.816 \\
\hline Fulgencio Antonio de Zavala & 6.500 & José Carrión (Obispo de Trujillo) & 3.500 \\
\hline
\end{tabular}




\section{N. ${ }^{\circ}$ 3. CONSIGNATARIOS CITADOS EN EL SOBORNO DEL ALCIDES}

\begin{tabular}{|c|c|c|c|}
\hline $\begin{array}{l}\text { CONSIGNATARIOS } \\
\text { (N. } .^{\circ} \text { de remesas) }\end{array}$ & $\begin{array}{l}\text { PESOS } \\
\text { TOTAL }\end{array}$ & $\begin{array}{l}\text { CONSIGNATARIOS } \\
\text { (N. } .^{\circ} \text { de remesas) }\end{array}$ & $\begin{array}{l}\text { PESOS } \\
\text { TOTAL }\end{array}$ \\
\hline Domingo de Vea-Murguía (2) & $88.244,4$ & Luciano Murrieta (1) & 8.000 \\
\hline José Vea-Murguía (1) & $43.004,6$ & Pablo Villanueva (3) & 8.000 \\
\hline Nicolás Herrán (10) & 24.430 & Juan Pértica (3) & $7.560,7$ \\
\hline Sobrinos de Aguerrevere y Lostra (10) & $22.047,8$ & Juan de Llano y Campo (5) & $7.560,7$ \\
\hline José Xavier Zuloaga (2) & $21.640,4$ & José Alvaredo e Hijos (1) & 7.000 \\
\hline Pedro Regalado del Campo (4) & $19.820,4$ & Manuel Micheo (1) & 7.000 \\
\hline Juan Antonio de Aramburu (6) & 19.000 & Nicolás Milanos (2) & 6.500 \\
\hline Juan Matías de Vertiz (3) & 18.100 & Juan Ranger (1) & $6.395,2$ \\
\hline Tomás de Urrutia (11) & $17.844,8$ & Fermín Elizalde (1) & 6.000 \\
\hline José Antonio de Albizuri (4) & $16.981,4$ & Martín de Mújica (1) & 6.000 \\
\hline Juan Antonio Llorente (7) & $15.573,5$ & María Ana Compaino (1) & $5.929,4$ \\
\hline Bartolomé de Lopetedi (3) & 13.082 & Luis Gargollo (2) & 5.500 \\
\hline Luis Francisco de Gardeazabal (4) & 12.200 & Domingo Ochoa de Zuazola (1) & 5.000 \\
\hline José Francisco Portela (3) & 11.050 & Simón Agreda (2) & 5.000 \\
\hline Domingo de Aramburu (1) & 11.000 & Pedro Zulueta, padre e hijo (2) & 4.816 \\
\hline José Joaquín de Aguirre (2) & $10.603,4$ & Paúl Larrieta y Cía. (2) & $4.712,4$ \\
\hline Juan Sanz de Santo Domingo (3) & 10.500 & Miguel de la Lastra (2) & 4.250 \\
\hline Sres. de Vea-Murguía y Lizaur (2) & 10.300 & Juan Valdez (1) & $4.246,2$ \\
\hline Ignacio Sobrado (1) & 10.000 & Juan Ferrer (1) & 4.000 \\
\hline Caja de Soldadas (1) & 10.000 & Miguel Almorza (1) & 4.000 \\
\hline Antonio Artechea (4) & 8.600 & Juan Antonio de Uriarte (3) & 3.300 \\
\hline José Romero Campo (5) & 8.550 & & \\
\hline
\end{tabular}


JESÚS RUIZ DE GORDEJUELA URQUIJO

\section{N. ${ }^{\circ}$ 4. EMBARCACIONES COMERCIALES ENTRE CÁDIZ Y EL CALLAO 1816-1820}

\begin{tabular}{|c|c|c|c|}
\hline EMBARCACIÓN & ARMADOR & CAPITÁN/MAESTRE & FECHA \\
\hline Veloz Pasajera & & & 1816 \\
\hline La Aurora & & & 1816 \\
\hline La Venganza & & & 1816 \\
\hline $\begin{array}{l}\text { El Mexicano (se descolgó } \\
\text { en Canarias) }\end{array}$ & & & 1816 \\
\hline $\begin{array}{l}\text { La Rosalía alias } \\
\text { La Xerezana }\end{array}$ & & & 1816 \\
\hline $\begin{array}{l}\text { Fragata de guerra } \\
\text { La Esmeralda }\end{array}$ & & Luis Coig (c) & 1817 \\
\hline $\begin{array}{l}\text { Nuestra Señora de la } \\
\text { Asunción, alias } \\
\text { La Vigarrena }\end{array}$ & $\begin{array}{l}\text { Francisco de Paula } \\
\text { Ugarte }\end{array}$ & & Idem \\
\hline $\begin{array}{l}\text { San José alias } \\
\text { Rey Fernando }\end{array}$ & $\begin{array}{l}\text { Real Compañía de } \\
\text { Filipinas }\end{array}$ & Alonso de la Riva (c) & Idem \\
\hline $\begin{array}{l}\text { Santa Catalina alias } \\
\text { La Tagle }\end{array}$ & Antonio Baras & $\begin{array}{l}\text { Agustín de Larrazaval } \\
\text { (c) }(\mathrm{m})\end{array}$ & Idem \\
\hline Primorosa Mariana & & José Arrarte (m) & Idem \\
\hline Minerva & & $\begin{array}{l}\text { José Vicente de Jáuregui } \\
(\mathrm{m})\end{array}$ & Idem \\
\hline La Castilla & & & Idem \\
\hline San Juan Bautista & & & Idem \\
\hline La Perla & Juan Antonio Llorente & & Idem \\
\hline $\begin{array}{l}\text { San Miguel alias } \\
\text { El Comercio de Lima }\end{array}$ & $\begin{array}{l}\text { José de Santiago } \\
\text { y Rotalde }\end{array}$ & Antonio Sarría (m) & Idem \\
\hline $\begin{array}{l}\text { Nuestra Reina de los } \\
\text { Ángeles }\end{array}$ & & & Idem \\
\hline $\begin{array}{l}\text { Los Tres Hermanos alias } \\
\text { La Vascongada }\end{array}$ & & Juan Bautista Gana & 1817 \\
\hline La Preciosa & $\begin{array}{l}\text { Francisco Xavier de } \\
\text { Izcue }\end{array}$ & & 1817 \\
\hline Marqués de la Romana & José Manuel de Ugarte & & 1817 \\
\hline La Rosalía & & & 1817 \\
\hline $\begin{array}{l}\text { San Antonio alias } \\
\text { La Vicenta }\end{array}$ & Viuda de Artechea & & 1817 \\
\hline $\begin{array}{l}\text { Nuestra Señora de la } \\
\text { Aurora }\end{array}$ & Joaquín Fco. de Luchi & Francisco J. de Luchi (m) & 1818 \\
\hline
\end{tabular}


EL COMERCIO GADITANO CON EL PERÚ ENTRE 1814 Y 1826

\section{N. ${ }^{\circ}$ 4. EMBARCACIONES COMERCIALES ENTRE CÁDIZ Y EL CALLAO 1816-1820 (continuación)}

\begin{tabular}{|c|c|c|c|}
\hline EMBARCACIÓN & ARMADOR & CAPITÁN/MAESTRE & FECHA \\
\hline $\begin{array}{l}\text { San Antonio alias } \\
\text { La Carlota }\end{array}$ & Antonio de Artechea & Juan Luis Marcaida (m) & 1818 \\
\hline Xaviera alias Warren & Ventura Imaña & $\begin{array}{l}\text { Juan Gener (c) y } \\
\text { Francisco Xavier de los } \\
\text { Ríos (m) }\end{array}$ & 1818 \\
\hline $\begin{array}{l}\text { Fragata de guerra María } \\
\text { Isabel }\end{array}$ & & $\begin{array}{l}\text { Capitán de navío Manuel } \\
\text { del Castillo }\end{array}$ & 1818 Apresado \\
\hline $\begin{array}{l}\text { La Rosalía alias la } \\
\text { Jerezana }\end{array}$ & & Andrés Machaca (c) & 1818 Apresado \\
\hline El Alcides & Sres. Ruiz e Hijo Terry & & 1818 Apresado \\
\hline Magdalena & & Pedro Sonilla & 1818 Apresado \\
\hline Elena & & Antonio Zubiaga & 1818 Apresado \\
\hline Todos los Santos & & Juan Martín Elorriaga & $\begin{array}{l}\text { Vía de agua en } \\
\text { Tenerife }\end{array}$ \\
\hline Especulación & & Miguel Siloniz & 1818 \\
\hline Atocha & & Joaquín Sagasti & 1818 \\
\hline Santa maría & & Domingo Dobarán & 1818 \\
\hline $\begin{array}{l}\text { Esmeralda (fragata } \\
\text { guerra) }\end{array}$ & & & 1818 \\
\hline $\begin{array}{l}\text { Nuestra Señora de } \\
\text { Guadalupe alias } \\
\text { La Hermosa Mexicana }\end{array}$ & Señores Clausell y Dorca & & 1818 \\
\hline $\begin{array}{l}\text { Santa Rosa de Lima alias } \\
\text { La Centinela }\end{array}$ & $\begin{array}{l}\text { Miguel Cayetano } \\
\text { Almuerza }\end{array}$ & Martín de Zala (c) (m) & 1818 \\
\hline Navío San Telmo & & $\begin{array}{l}\text { Brigadier Rosendo } \\
\text { Porlier Saenz de } \\
\text { Asteguieta }\end{array}$ & $\begin{array}{c}1819 \\
\text { Desaparecido }\end{array}$ \\
\hline Fragata de guerra Prueba & & & 1819 \\
\hline Primorosa Mariana & & & 1819 \\
\hline $\begin{array}{l}\text { Santa Catalina alias } \\
\text { La Tagle }\end{array}$ & Antonio Baras & $\begin{array}{l}\text { Agustín de Larrazaval } \\
\text { (c) (m) }\end{array}$ & 1819 \\
\hline Especulación & & Miguel Siloniz & 1820 \\
\hline
\end{tabular}

